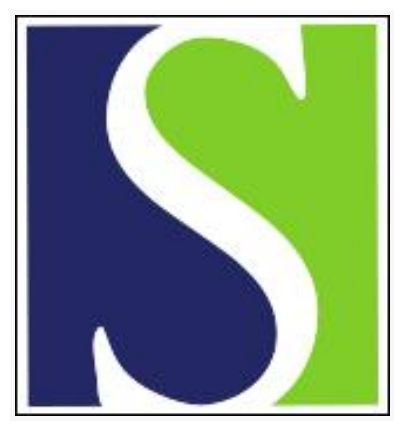

Scand J Work Environ Health 1991;17(6):398-403

https://doi.org/10.5271/sjweh.1687

Issue date: Dec 1991

Ocular exposure to solar ultraviolet and visible radiation at high latitudes.

by Hietanen $\mathrm{M}$

Affiliation: Institute of Occupational Health, Laboratory of Physics, Vantaa, Finland.

This article in PubMed: www.ncbi.nlm.nih.gov/pubmed/1788533

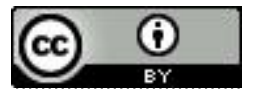




\title{
Ocular exposure to solar ultraviolet and visible radiation at high latitudes
}

\author{
by Maila Hietanen, $\mathrm{PhD}^{1}$
}

\begin{abstract}
HIETANEN M. Ocular exposure to solar ultraviolet and visible radiation at high latitudes. Scand $J$ Work Environ Health 1991;17:398-403. Exposure of the eyes to ultraviolet (UV) radiation and short wavelength light, blue light, from the sun was assessed under realistic geometric conditions. A spectroradiometer with a double monochromator was used to determine the spectral irradiance at 1-nm intervals within the wavelength range of $250-800 \mathrm{~nm}$. Biological weighting functions were used to calculate the blue-light radiance and the weighted UV irradiance. In addition, a photometer with a $1^{\circ}$ angle of view was used to measure the ambient luminance. The results indicate that sizable amounts of UV radiation and blue light can be reflected from different environmental surroundings. Hence various groups of outdoor workers seem to be at risk of chronic ocular overexposure to solar radiation. When occupational exposure limits for UV and visible radiation are revised, the risks of chronic exposure should receive more consideration than to date.
\end{abstract}

Key terms: blue light, irradiance, luminance, optical radiation, radiance, spectroradiometry, sun.

To be able to provide visual information, the eye has to be exposed to optical wavelengths of the electromagnetic spectrum. In addition to the indispensable visible region, the optical spectrum contains invisible wavelengths without any contribution to vision; hence in a physiological sense these wavelengths can be regarded as redundant. In the indoor work environment, electric welding arcs are typical examples of sources of hazardous invisible radiation (1-3). For outdoor workers, the most important source of optical radiation is the sun. The findings of recent studies have led to the conclusion that exposure of the eyes to the sun can cause acute and chronic damage (4-11).

Shortwave ultraviolet (UV) radiation has been shown to be an important etiologic agent for photokeratitis and photoconjuctivitis $(6,12,13)$. For both of these conditions, the initial symptoms (severe pain and discomfort, photophobia, and the sensation of sand in the eye) occur $1-12 \mathrm{~h}$ after exposure. However, the effects are reversible and usually disappear within a few days. The maximum spectral efficiency for causing photokeratitis and photoconjuctivitis is at 265-275 nm with the threshold radiant exposure of about $40 \mathrm{~J} \cdot \mathrm{m}^{-2}$ (14). In the long ultraviolet region (UV-A), the corneal damage threshold is several orders of magnitude higher, being of the order of $50 \cdot 10^{4} \mathrm{~J} \cdot \mathrm{m}^{-2}$ at $350 \mathrm{~nm}$ (15). This threshold differential may be considered to derive from the evolutionary process giving protection towards solar UV-A radiation, which reaches the earth in large amounts (15). Terrestrial UV radiation sharply

\footnotetext{
1 Institute of Occupational Health, Laboratory of Physics,
} Vantaa, Finland.

Reprint requests to: Dr M Hietanen, Institute of Occupational Health, Laboratory of Physics, Laajaniityntie 1, SF-01620 Vantaa, Finland. decreases below $300 \mathrm{~nm}$ due to absorption and scattering in the stratospheric ozone layer.

Accordingly, the comprehensive literature on the etiology of cataracts supports the concept that UV radiation is the most significant environmental contributing factor in the development of senile cataracts $(6$, 16-18). Several studies have also shown that opacities of the lens can be the result of either chronic lowlevel exposures or acute high-level UV doses (19-20). However, it has not adequately been determined whether either visible or infrared radiation is additive or synergistic in cases when there is combined exposure with UV radiation $(10,17)$. The current data lead to the conclusion that the danger to the lens from ambient infrared radiation is much less than that from UV radiation (10).

Recent investigations have also changed the earlier concept that exposure to bright light in amounts insufficient to cause thermal damage to the retina is harmless $(6,21-22)$. Several studies have shown that the shorter the wavelength of light, the more serious the retinal photochemical damage (23-26). Numerous epidemiologic investigations support the hypothesis that chronic exposure to shortwave visible radiation, blue light, is a contributing factor to the aging and degeneration of the retina $(27-31)$.

Typical blue-light damage results from staring at a solar eclipse. Solar retinitis and other macular trauma seem, however, to be partly reversible. Currently the best evidence suggests that macular damage resulting from viewing the sun with the unaided eye is photochemical and seems to be reversible. A thermal form of damage is caused by viewing the sun through gathering optics, such as binoculars. In this case the magnification of the sun's image at the retina results in true solar burn which causes an irreversible loss of vision $(23,32)$. 
Finally, several epidemiologic investigations have suggested that UV radiation could also be associated with the genesis of ocular melanoma (33-36). According to these studies, a positive correlation has been found between the rates for cancer of the eye and those for cutaneous melanoma, intense exposure to the sun being attributed to be the common risk factor. Accordingly, individuals with blue or grey eyes, fair hair, and light skin seem to have an elevated risk for ocular melanoma (33).

In general, the human eye is not subjected to prolonged exposure to powerful solar irradiance since it is protected by a natural aversion response (blink reflex, eye and head movement) against bright light, as well as by the brow ridges, eye lashes, and usually superior oblique position of the sun during periods of the shortest air path for solar radiation. However, in certain work situations reflected solar radiation can fall directly into the eyes. The aim of this study was to estimate ocular exposure to solar UV and visible radiation under actual geometric viewing conditions using spectroradiometric and photometric methods and various biological weighting functions.

\section{Materials and methods}

\section{Measurement procedures}

In this study, several spectral recordings of solar radiation were taken over a long period to provide sufficient data for realistic hazard analyses. The measurements were performed on sunny days during the summer, winter, and spring seasons in Vantaa, a suburb of Helsinki $\left(60^{\circ} 9^{\prime} \mathrm{N}\right)$.

A portable spectroradiometer (Optronic 742) was used to determine the spectral irradiance of UV radiation $(200-400 \mathrm{~nm})$ and light $(400-800 \mathrm{~nm})$. The spectroradiometer had a double monochromator with two concave holographic gratings separated by a slit. Two different diffusers were used, a teflon diffuser for the wavelength region of $250-400 \mathrm{~nm}$ and an opal diffuser to cover the visible spectrum from 380 to $800 \mathrm{~nm}$. The dynamic range of the spectroradiometer $\left(10^{-9}-10^{-3} \mathrm{~W} \cdot \mathrm{cm}^{-2} \cdot \mathrm{nm}^{-1}\right)$ was extended to $0.1 \mathrm{~W} \cdot \mathrm{cm}^{-2} \cdot \mathrm{nm}^{-1}$ with the use of a neutral density filter $(1 \%)$. The detector attached to the monochromator was a photomultiplier tube. A digitally controlled stepping motor and associated electronics provided automatic wavelength scanning at 1-nm intervals. The spectroradiometric instrumentation was controlled with a microcomputer (Toshiba 3200).

The luminance of the reflected solar radiation was taken with a photometer (Brüel \& Kjaer model 1101). The combination of a silicon detector and a weighting filter matched the meter to the luminous efficiency function for phototopic vision.

The calibration of the spectroradiometer was performed by secondary standard sources traceable to the United States National Institute of Technologies and
Standards (NITS). At wavelengths of $250-300 \mathrm{~nm}$ a stabilized deuterium arc lamp (Optronic $\mathrm{M}-40$ ) was used, while at longer wavelengths the detectors were calibrated against a secondary tungsten halogen standard (Optronic $\mathrm{M}-356$ ). The accuracy announced by the NITS for the deuterium source was $\pm 6 \%$. The accuracy for the calibrated halogen lamp was $\pm 3 \%$ at $300 \mathrm{~nm}$ and $\pm 2 \%$ at $400 \mathrm{~nm}$. The calibration of the luminance meters was carried out against a standard illumination source A (3). The accuracy was $\pm 3 \%$, and the response to UV radiation less than $1 \%$.

\section{Recommended ocular exposure limits}

Ultraviolet radiation. The results of the UV measurements were evaluated on the basis of two different recommendations.

The well-known threshold limit values (TLV) set by the American Conference of Governmental Industrial Hygienists (ACGIH) for occupational exposure of the eye to UV radiation are reevaluated and published yearly. In the region $320-400 \mathrm{~nm}$, the radiant exposure should be less than $1 \mathrm{~J} \cdot \mathrm{cm}^{-2}$ during $1000 \mathrm{~s}$. For durations greater than $1000 \mathrm{~s}$, the total irradiance should be less than $10 \mathrm{~W} \cdot \mathrm{m}^{-2}$. For wavelengths between 200 and $315 \mathrm{~nm}$, the effective irradiance $\left(E_{\text {eff }}\right)$ was determined with the use of the spectral effectiveness curve established by the ACGIH. As a comparison, spectral weighting was also applied to UV-A radiation according to the newest ACGIH revision (37).

The Finnish Ministry of Social Affairs and Health has recently given a recommendation primarily for limiting exposure of the general public to artificial UV sources, such as solaria (38). It is based on the biological action spectrum recommended by the International Committee of Illumination (CIE) (39). The weighted effective radiant exposure $\left(\mathrm{H}_{\mathrm{be}}\right)$ adopted by the CIE is given by the following equation:

$$
\mathrm{H}_{\mathrm{be}}=\sum_{100}^{400} \mathrm{C}_{\lambda} \mathrm{H}_{\lambda} \Delta \lambda
$$

(equation 1)

where $C_{\lambda}$ is the relative spectral effectiveness expressed in the analytical form in table $1, \mathrm{H}_{\lambda}$ is the exposure of wavelength $\lambda$, and $\Delta \lambda$ is the bandwidth in nanometers.

The Finnish recommendation for UV radiation contains the following three separate points: (i) a daily limit of $50 \mathrm{~J} \cdot \mathrm{m}^{-2}$ for $\mathrm{H}_{\mathrm{be}}$, (ii) an unweighted irradiance limit of $10 \mathrm{~W} \cdot \mathrm{m}^{-2}$ averaged over $1000 \mathrm{~s}$, and

Table 1. Spectral efficiency of the CIE action curve (39). (CIE = International Committee of Illumination)

\begin{tabular}{ll}
\hline $\begin{array}{l}\text { Wavelength }(\lambda) \\
(\mathrm{nm})\end{array}$ & Spectral efficiency $\left(\mathrm{C}_{\lambda}\right)$ \\
\hline$\lambda \leq 298$ & 1 \\
$298 \leq \lambda \leq 328$ & $10^{0.094(298-\lambda)}$ \\
$328 \leq \lambda \leq 400$ & $10^{0.015(139-\lambda)}$ \\
\hline
\end{tabular}


(iii) maximum yearly cumulative exposure of 25 $\mathrm{kJ} \cdot \mathrm{m}^{-2}$ for $\mathrm{H}_{\mathrm{be}}$.

Visible light. The limits recommended by the ACGIH to protect the eye against photochemical injury from chronic blue-light exposure were used to evaluate exposure to shortwave visible radiation. The hazard was assessed from calculations of the blue-light weighted radiance $\left(L_{B}\right)(37)$.

The spectral radiance was calculated from the measured spectral irradiance $\left(E_{\lambda}\right)$ divided by the solid angle subtended by the source. For an extended source for which $\mathrm{L}_{\mathrm{B}}$ exceeds $100 \mathrm{~W} \cdot \mathrm{m}^{-2} \cdot \mathrm{sr}^{-1}$, the permissible exposure duration $\left(t_{\max }\right)$ in seconds can be calculated by the following equation:

$$
\mathrm{t}_{\max }=100 \mathrm{~J} \cdot \mathrm{cm}^{-2} \cdot \mathrm{sr}^{-1} / \mathrm{L}_{\mathrm{B}} \text {. }
$$

(equation 2)

For light sources subtending a plane angle less than $11 \mathrm{mrad}$, the exposure was assessed from calculations of the blue-light weighted irradiance $\left(\mathrm{E}_{\mathrm{B}}\right)(37)$. The $t_{\max }$ in seconds for a point source in which $E_{B}$ exceeds $1 \mu \mathrm{W} \cdot \mathrm{cm}^{-2}$ was calculated by the following equation:

$$
\mathrm{t}_{\max }=10 \mathrm{~mJ} \cdot \mathrm{cm}^{-2} / \mathrm{E}_{\mathrm{B}}
$$

The present TLV requires detailed spectral data of a light source whose luminance exceeds $10^{4} \mathrm{~cd} \cdot \mathrm{m}^{-2}$ (37). According to earlier recommendations, ocular exposure to luminances exceeding $10^{4} \mathrm{~cd} \cdot \mathrm{m}^{-2}$ should be limited to $10 \mathrm{~s}(3)$.

\section{Results}

The UV irradiances measured on clear, sunny days in different seasons are listed in table 2 . The detector was directed both towards the sun and in different angles of view simulating the actual position of the eye. The spectra were recorded at wavelengths of $250-400 \mathrm{~nm}$ at relatively small Zenith angles $\left( \pm 20^{\circ}\right)$ around noon.

The first column of irradiance in table 2 indicates the unweighted UV-A irradiance, which varied from 18 to $48 \mathrm{~W} \cdot \mathrm{m}^{-2}$. The second column indicates ACGIH-weighted actinic UV radiation $(200-315 \mathrm{~nm})$, while the following two columns are the total UV irradiances $(200-400 \mathrm{~nm})$ weighted according to the efficiency factors adopted by the ACGIH and the CIE, respectively. The permissible daily exposure times for unprotected eyes were determined on the basis of the most restrictive limit, which appeared to be the daily limit of $50 \mathrm{~J} \cdot \mathrm{m}^{-2}$ of the CIE.

Reflection measurements were performed in the month of March on a bright sunny day. Figure 1 shows a typical UV spectrum of reflections from fresh snow. Note that solar UV radiation was reflected even at short (UV-B) wavelengths.

The solar blue-light irradiance measured on various days of a year is presented in table 3 . The sun subtends an average angle of $9.31 \mathrm{mrad}$, and hence point source criteria must be applied in evaluations of direct ocular exposure to the visible spectrum of the sun (equation 3). The safe exposure time was only a few seconds for unprotected eyes, as can be seen in table 3 .

Table 4 summarizes the reflected blue-light radiance and luminance of fresh and icy snow. The measurements were taken at an extended angle $\left(2_{\pi} \mathrm{sr}\right)$ with the detector directed to $30^{\circ}$ below the horizontal plane. The blue-light radiances recorded were less than the recommended TLV $\left(100 \mathrm{Wm}^{-2} \cdot \mathrm{sr}^{-1}\right)$. The luminance of the reflections was, however, higher than the proposed value of $10 \mathrm{kcd} \cdot \mathrm{m}^{-2}$ for long exposures.

An example of a typical spectral radiance of the solar light reflected from a snow field is shown in figure 2. The shape of the spectrum is similar to that of the direct sunlight and indicates the high reflectivity of snow.

Table 2. Solar ultraviolet (UV) irradiance measured on various days at noon with the corresponding safe daily exposure times

\begin{tabular}{|c|c|c|c|c|c|}
\hline \multirow{2}{*}{ Date } & \multicolumn{4}{|c|}{ Irradiance $\left(\mathrm{W} \cdot \mathrm{m}^{-2}\right)$} & \multirow{2}{*}{$\mathrm{t}(\min )$} \\
\hline & $U V \cdot A^{a}$ & $U_{\text {eff }}{ }^{b}$ & $\mathrm{UV}_{\mathrm{ACGIH}}{ }^{\mathrm{c}}$ & $\mathrm{UV}_{\mathrm{CIE}^{\mathrm{d}}}$ & \\
\hline $\begin{array}{l}26 \text { May } \\
05 \text { July } \\
09 \text { August } \\
14 \text { March } \\
14 \text { March }\end{array}$ & $\begin{array}{l}33 \\
48 \\
48 \\
18 \\
18\end{array}$ & $\begin{array}{l}0.007 \\
0.023 \\
0.028 \\
0.0009 \\
0.002\end{array}$ & $\begin{array}{l}0.014 \\
0.032 \\
0.037 \\
0.004 \\
0.005\end{array}$ & $\begin{array}{l}0.063 \\
0.127 \\
0.137 \\
0.020 \\
0.023\end{array}$ & $\begin{array}{l}4.8^{\mathrm{e}} \\
3.4^{\mathrm{e}} \\
3.3^{\mathrm{e}} \\
9.0^{\mathrm{f}} \\
8.8^{9}\end{array}$ \\
\hline
\end{tabular}
(t), (ACGIH = American Conference of Governmental Industrial Hygienists, ClE = International Committee of Illumination)

a Unweighted UV long-wave irradiance $(320-400 \mathrm{~nm})$.

b Weighted effective UV irradiance $(200-400 \mathrm{~nm})$

c ACGIH-weighted total UV irradiance $(200-400 \mathrm{~nm})$.

d CIE-weighted total UV irradiance $(200-400 \mathrm{~nm})$.

e Detector directed towards the sun.

$f$ Detector directed horizontally.

- Detector directed towards a fresh. snow field. 


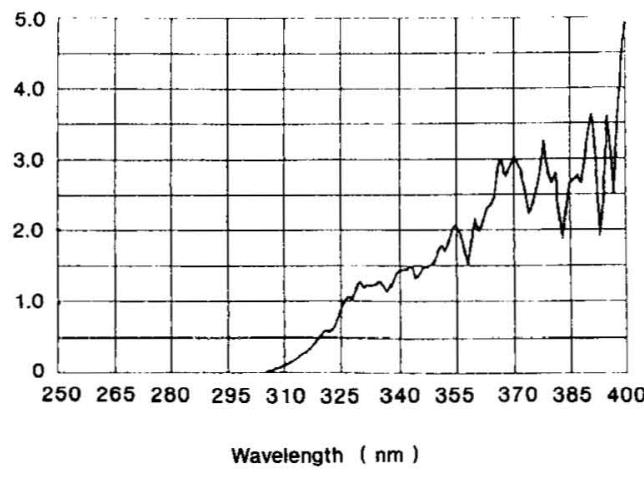

Figure 1. Ultraviolet spectrum of the ambient solar radiation reflected from snow at noontime (the sun near Zenith).

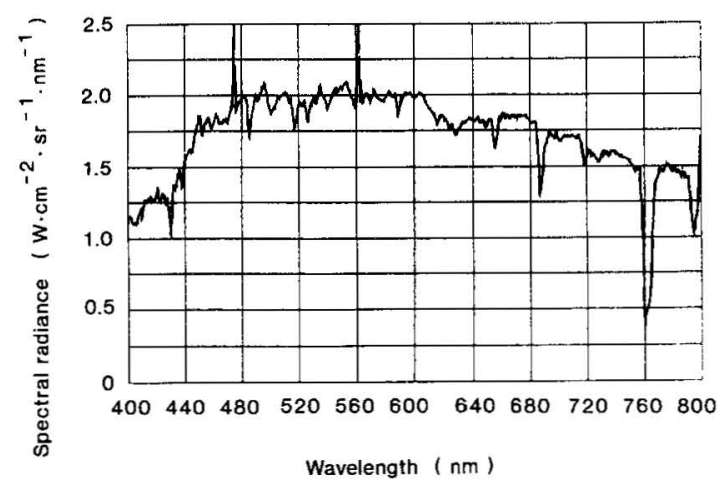

Figure 2. Spectral radiance of solar visible radiation reflected from snow at noontime (the sun near Zenith).

\section{Discussion}

The results of this study (tables 2 and 3 ) are in accord with the findings of earlier studies. From an occupational health standpoint, the measurement data on ocular exposure to solar radiation in the northern latitudes are, however, scanty. The ambient levels of solar radiation have mainly been measured for meteorological purposes (40-42). The calculated annual exposure levels in these studies quote the amount of radiation falling on a horizontal surface and cannot be used in the assessment of solar exposure of the eyes. Most reports on the effects of solar radiation on humans are concerned only with ultraviolet exposure $(2,17,43)$.

For the analysis of ocular exposure conditions, some peculiarities of the northern solar environment in comparison with other global regions should be recognized. First, at latitudes higher than about $67^{\circ}$ (eg, Rovanie$\mathrm{mi}$, Finland), the sun does not go below the horizon during the period from about the first of June to the 15th of July. At the latitude of Helsinki $\left(60^{\circ} 9^{\prime}\right)$, as well, the sun remains above the horizon about $19 \mathrm{~h}$
Table 3. Blue-light weighted irradiance $\left(E_{B}\right)$ of the sun at noon with the corresponding recommended maximum direct ocular exposure times (t).

\begin{tabular}{lcr}
\hline Date & $\mathrm{E}_{\mathrm{B}}\left(\mathrm{W} \cdot \mathrm{m}^{-2}\right)$ & $\mathrm{t}(\mathrm{s})$ \\
\hline 26 May 1989 & 71.7 & $<2$ \\
05 July 1989 & 92.5 & $\sim 1$ \\
16 November 1989 & 14.9 & 6 \\
\hline
\end{tabular}

Table 4. Blue-light weighted radiance $\left(L_{B}\right)$ and luminance $\left(L_{v}\right)$ of solar radiation reflected from snow and ice measured at noon.

\begin{tabular}{lccl}
\hline Date & $\begin{array}{c}\mathrm{L}_{\mathrm{B}} \\
\left(\mathrm{W} \cdot \mathrm{m}^{-2} \mathrm{sr}^{-1}\right)\left(\mathrm{kcd} \cdot \mathrm{m}^{-2}\right)\end{array}$ & $\begin{array}{l}\text { Reflective } \\
\text { surface }\end{array}$ \\
\hline 13 March 1990 & 2.81 & 18.5 & Snow \\
13 March 1990 & 11.37 & 24.5 & Snow \\
13 March 1990 & 9.65 & 21.5 & Snow \\
14 March 1990 & 6.78 & 32.5 & Snow \\
14 March 1990 & $\cdots$ & 51 & lce \\
\hline
\end{tabular}

Table 5. Maximum and minimum noon-time heights of the sun as seen in various global locations.

\begin{tabular}{llll}
\hline & & \multicolumn{2}{c}{$\begin{array}{c}\text { Solar height } \\
\text { at noon }\end{array}$} \\
\cline { 3 - 4 } Place & Latitude & \multicolumn{2}{c}{ Maximum Minimum } \\
\hline Rovaniemi (Finland) & $66^{\circ} 30^{\prime} \mathrm{N}$ & $46^{\circ} 54^{\prime}$ & $1^{\circ} 33^{\prime}$ \\
Helsinki & $60^{\circ} 9^{\prime} \mathrm{N}$ & $53^{\circ} 17^{\prime}$ & $6^{\circ} 33^{\prime}$ \\
New York & $40^{\circ} 42^{\prime} \mathrm{N}$ & $72^{\circ} 45^{\prime}$ & $25^{\circ} 51^{\prime}$ \\
Cairo & $30^{\circ} \mathrm{N}$ & $83^{\circ} 27^{\prime}$ & $36^{\circ} 33^{\prime}$ \\
\hline
\end{tabular}

of the day during the same period. In other words the daily duration of solar exposure is long during summer.

Second, the altitude of the sun is predominantly low in Finland. The maximum and minimum solar heights at noon, as occurs in some cities at different global latitudes, are given in table 5 . As can be seen, the sun, as viewed from Helsinki, is never higher than $53^{\circ} 17^{\prime}$ compared, for example, with the maximum height of $83^{\circ} 27^{\prime}$ for Cairo and $72^{\circ} 45^{\prime}$ for New York. Therefore, it is difficult to avoid at least peripheral exposure of the eyes to the sun, especially during clear spring and autumn days. In addition, the clean air brought in by the winds from the sea guarantees good visibility of the sun, compared with many southern areas. In general, it is considered uncomfortable to view the sunset until the elevation angle is less than about $5^{\circ}(11)$. In Finland, because of the clear air, comfortable viewing is often possible only below $3^{\circ}$.

The third contributing factor to hazardous ocular exposure is the reflected solar radiation from snow and ice, which are important components of the environ- 
ment in most parts of Finland during the winter and spring. On the basis of the results of this study, and because photokeratitis is often experienced after exposure to reflections from snow, it can be estimated that the eyes are frequently exposed to a daily UV-B radiation dose higher than the threshold for corneal damage $\left(40 \mathrm{~J} \cdot \mathrm{m}^{-2}\right)$. In addition the damage threshold for UV-A $\left(50 \cdot 10^{4} \mathrm{~J} \cdot \mathrm{m}^{-2}\right)$ can be exceeded (table 2, footnote $\mathrm{g}$ ).

Unintentional exposure of the retina to high levels of incoherent visible radiation is very rare. In our previous report on television workers long-term risks were found in association with white-light source usage (44). The results of this study extend previous ones on outdoor work conditions. As regards occupational protection against industrial sources, the present standards for welding eye protectors are based on a luminance of $730 \mathrm{~cd} \cdot \mathrm{m}^{-2}$, a level regarded as safe and comfortable for direct viewing. Recently, higher values $(2-10$ $\mathrm{kcd} \cdot \mathrm{m}^{-2}$ ) have been suggested on the basis of results from field experiments (45).

Compared with the data of this study, the aforementioned safe luminances are clearly less than the luminance reflected from snow (table 4). On the contrary, the recommended TLV for blue-light radiance is about 10 times higher than the values measured from snow. However, macular disorders caused by ambient solar radiation have been reported as hazards of sunbathing without sun gazing $(46,47)$. Similarly, a report of young adults who developed solar retinopathy without direct viewing of the sun has recently been published (48). These findings, together with the common feeling of unbearable glare of reflected light from snow, lead to the suggestion that the TLV for blue-light radiance should be limited to 10 or $20 \mathrm{~W} \cdot \mathrm{m}^{-2} \cdot \mathrm{sr}^{-1}$ instead of the presently proposed $100 \mathrm{~W} \cdot \mathrm{m}^{-2} \cdot \mathrm{sr}^{-1}$.

In summary, the greatest contributor to exposure of the eyes to solar UV radiation and blue light during spring and winter at northern latitudes is the reflection from the snow, while reflection from water, sand, and concrete may become significant during summer. In the future, the concept of reduced ozone in the atmosphere of the northern latitudes must also be taken into account. In particular, outdoor workers (eg, farmers, fishermen, merchants at marketplaces, and personnel at skiing centers) seem to be at risk of ocular overexposure from ambient solar radiation. The need for reliable sunglasses which filter out UV radiation and attenuate blue-light wavelengths is evident in such situations. Usage of such eye protectors would eliminate the most hazardous wavelengths and improve image quality while only minimally affecting image color balance (7).

Finally, it would appear that in the preparation of future revisions to the occupational and environmental safety standards, both for UV radiation and visible light, the risk of ocular damage due to chronic exposure should be considered more carefully than has been the case so far.

\section{Acknowledgments}

I wish to thank J Lappalainen, MSc, and P von Nandelstadh, BSc(Eng), for their skillful assistance with the measurements and Ms U Roine for her kind help in preparing the manuscript.

\section{References}

1. Eriksen P. Time resolved optical spectra from MIG welding arc ignitions. Am Ind Hyg Assoc J 1985;46:101-4.

2. McKinlay AF, Harlen F, Whillock MJ. Hazards of optical radiation: a guide to sources, uses and safety. Bristol: IOP Publishing Ltd, 1988.

3. Sliney DH, Wolbarsht ML. Safety with lasers and other optical sources: a comprehensive handbook. New York, NY: Plenum Press, 1980.

4. Giese AC. Living with our sun's ultraviolet rays. New York, NY: Plenum Press, 1976.

5. Ham WT, Mueller HA, Williams RC, Geeraets WJ. Ocular hazards from viewing the sun unprotected and through various windows and filters. Appl Optics 1973; 12:2122-9.

6. Lerman S. Radiant energy and the eye. New York, NY: MacMillan, 1980.

7. Mainster MA, Ham WT, Delori F. Potential retinal hazards: instrument and environmental light sources. Ophthalmology 1983;90:927-31.

8. Marshall J, Greenstein V, Kline D, Owsley C, Werner JS. Optical radiation and the aged eye. In: Waxler $M$, Hitchins VM, ed. Optical radiation and visual health. Boca Raton, FL: CRC Press, 1986:103-24.

9. Marshall J. Ultraviolet radiation and the eye. In: Passhier WF, Bosnjakovic BFM, ed. Human exposure to ultraviolet radiation: risks and regulations. Amsterdam: Elsevier Science Publishers, 1987:125-42.

10. Pitts DG, Cameron LL, Jose JG, et al. Optical radiation and cataracts. In: Waxler M, Hitchins VM, ed. Optical radiation and visual health. Boca Raton, FL: CRC Press, 1986:5-41.

11. Sliney DH. Eye protective techniques for bright light. Ophthalmology 1983;90:937-44.

12. Blumthaler M, Ambach W, Daxecker F. Keratitis solarischaracteristics of exposure dose and estimation of the threshold limit. In: Passhier WF, Bosnjakovic BFM, ed. Human exposure to ultraviolet radiation: risks and regulations. Amsterdam: Elsevier Science Publishers, 1987: 229-34.

13. Wittenberg S. Solar radiation and the eye: a review of knowledge relevant to eye care. Am J Optom Physiol Opt 1986;63:676-89.

14. Pitts DG. The ocular ultraviolet action spectrum and protection criteria. Health Phys 1973;25:559-66.

15. Zuclich JA. Ultraviolet-induced photochemical damage in ocular tissues. Health Phys 1989;56:671-82.

16. Sliney DH. Estimating the solar ultraviolet exposure to an intraocular lens implant. J Cataract Refract Surg 1987;13:296-301.

17. Sliney DH. Physical factors in cataractogenesis: ambient ultraviolet radiation and temperature. Invest Ophthalmol Vis Sci 1986;781-90.

18. Waxler M. Long-term visual health problems: optical radiation risks. In: Waxler $M$, Hitchins VM, ed. Optical radiation and visual health. Boca Raton, FL: CRC Press, 1986:183-204.

19. Söderberg PG. Experimental cataract induced by ultraviolet radiation. Acta Ophthalmol 1990;68(suppl 196): $1-77$.

20. Zigman S. Near UV-radiation effect on the lens and retina. In: Passhier WF, Bosnjakovic BFM, ed. Human exposure to ultraviolet radiation: risks and regulations. 
Amsterdam: Elsevier Science Publishers, 1987:143-46.

21. Harwerth RS, Sperling HG. Prolonged color blindness induced by intense spectral light in rhesus monkeys. Science 1971;174:520-23.

22. Kuwabara T, Gorn RA. Retinal damage by visible light. Arch Ophthalmol 1968;79:69-78.

23. Ham WT, Allen RG, Feeney-Burns L, et al. The involvement of the retinal pigment epithelium (RPE). In: Waxler M, Hitchins VM, ed. Optical radiation and visual health. Boca Raton, FL: CRC Press, 1986:44-67.

24. Ham WT, Muller AA, Sliney DH. Retinal sensitivity to damage from short wavelength light. Nature 1976;260: 153-5.

25. Ham WT, Ruffolo JJ, Mueller HA, Gurry D. The nature of retinal radiation damage: dependence of wavelength, power level and exposure time. Vision Res 1980; 20:1105-11.

26. Zwick $\mathrm{H}$. Visual functional changes associated with lowlevel light effects. Health Phys 1989;56:657-63.

27. Ham WT. Ocular hazards of light sources: review of current knowledge. J Occup Med 1983;25:101-3.

28. Heriot WS. Light and the retinal pigment epithelium: the link in senile macular degeneration? In: CronlyDillon J, Rosen ES, Marshall J, ed. Hazards of light. Oxford: Pergamon Press, 1986:187-96.

29. Lanum J. The damaging effects of light on the retina: empirical findings, theoretical and practical implications. Surv Opthalmol 1978;22:221-49.

30. Marshall J. Radiation and the ageing eye. Ophthalmol Physiol Opt 1985;3:241-63.

31. Marshall J. The ageing retina: physiology or pathology. Eye 1987;2:282-95.

32. Mainster MA. Solar retinitis, photic maculopathy and the pseudophatic eye. Am Intraocular Implant Soc J 1978;4:84-6.

33. Gallagher RP, Elwood JM, Rootman J, et al. Risk factors for ocular melanoma - Western Canada melanoma study. J Natl Cancer Inst 1985;74:775-8.

34. Hakulinen T, Teppo L, Saxen E. Cancer of the eye: a review of trends and differentials. World Health Stat Q 1987;31:143- 58 .

35. Tucker MA, Shields JA, Hartge P, Augsburger J, Hoover RN, Fraumeni JF. Sunlight as a risk factor for intraocular malignant melanoma. New Engl J Med 1985; 313:789-92.

36. Waterhouse J, Muir C, Shanmugaratnam K, Powell J. Cancer incidence in five continents. Lyon: International
Agency for Research on Cancer, 1982. (IARC scientific publications; no 4.)

37. American Conference of Governmental Industrial Hygienists (ACGIH). Threshold limit values and biological exposure indices for 1989-90. Cincinnati, OH: ACGIH, 1989.

38. Ministry of Social Affairs and Health. Sosiaali- ja terveysministeriön päätös ionisoimattoman säteilyn altistusrajoista. [Exposure limits on non-ionizing radiation]. Helsinki: Ministry of Social Affairs and Health, 1990. (Decision no 200.) (In Finnish and Swedish.)

39. Commission International de l'Eclairage (CIE). Research note of a reference action spectrum for ultraviolet induced erythema in human skin. CIE J 1987;6:17-22.

40. Josefsson W. Solar ultraviolet radiation in Sweden. Norrköping: Swedish Meteorological and Hydrological Institute, 1986. (SMHI report; no 53.)

41. Livingston W. Landscape as viewed in the $320-\mathrm{nm}$ ultraviolet. J Opt Soc Am 1983;73:1653-7.

42. Wester U. Solar ultraviolet radiation on the Canary Islands and in Sweden: a comparison of irradiance levels. In: Passhier WF, Bosnjakovic BFM, ed. Human exposure to ultraviolet radiation: risks and regulations. Amsterdam: Elsevier Science Publishers, 1987:275-9.

43. Kromann N, Wulff HC, Eriksen P, Brodthagen H. Relative ultraviolet spectral intensity of direct solar radiation, sky radiation and surface reflections. Photodermatology 1986;3:73-82.

44. Hietanen M, Hoikkala M. Ultraviolet radiation and blue light from photofloods in television studios and theaters. Health Phys 1990;59:193-8.

45. Eriksen P: Occupational applications of ultraviolet radiation: risk evaluation and protection techniques. In: Passhier WJ, Bosnjakovic BFM, ed. Human exposure to ultraviolet radiation: risks and regulations. Amsterdam: Elsevier Science Publishers, 1987:317-30.

46. Ridgeway A. Solar retinopathy. Br Med J 1967;3: 678-9.

47. Lawwill $T$. Three major pathologic processes caused by light in the primate retina: a search for mechanisms. Trans Am Ophthalmol Soc 1982;80:518-79.

48. Yannuzzi LA, Fisher YL, Krueger A, Slakter J. Solar retinopathy: a photobiological and geophysical analysis. Trans Am Opthalmol Soc 1987;85:120—58.

Received for publication: 13 August 1990 